\title{
Prevalence of Nonreactive Non-Stress Test in Low Versus High Risk Pregnancy
}

\author{
Tarinee Manchana MD*, Pinyada Panyavaranant MD, Patou Tantbironj MD, Porntip Sirayapiwat MD, Ruangsak Lertkachonsuk MD \\ and Surang Triratanachat MD
}

Department of Obstetrics and Gynecology, Faculty of Medicine, Chulalongkorn University and King Chulalongkorn Memorial Hospital, Bangkok, 10330, Thailand

${ }^{*}$ Corresponding Author: Tarinee Manchana, Department of Obstetrics and Gynecology, Faculty of Medicine, Chulalongkorn University and King Chulalongkorn Memorial Hospital, Bangkok 10330, Thailand; Tel: 66-2-2564000 (ext) 2114; Fax: 66-2-2527376; E-mail: Tarinee.M@chula.ac.th

Received: December 08, 2018; Accepted: December 21, 2018; Published: January 08, 2019;

\begin{abstract}
Objective: To determine the prevalence of non-reactive non-stress test (NST) in low risk and high risk pregnant women.

Materials and Methods: This prospective cohort study enrolled pregnant women with gestational age of 32 weeks or more who had been offered NST by their obstetricians at the antenatal clinic, King Chulalongkorn Memorial Hospital. High risk group were defined as having any maternal, fetal or placental risk factors. The NST result was interpreted by at least two obstetricians. All participants were followed until delivery and perinatal outcomes were recorded.

Results: A total number of 1,168 participants with 1,261 NST tests were included. 782 tests (62\%) were offered to low risk and 479 tests (38\%) to high risk group. Decrease in weight and maternal diabetes mellitus was the most common indication for low risk and high risk group, respectively. Overall prevalence of non-reactive NST was $0.32 \%$ ( $0.38 \%$ in low risk and $0.21 \%$ in high risk group). Only one newborn with non-reactive NST in high risk group was admitted in the NICU due to meconium aspiration syndrome. However, there was no significant association between non-reactive NST and obstetric risks or adverse perinatal outcomes.
\end{abstract}

Conclusion: The prevalence of non-reactive NST in this study was only $0.32 \%$. NST is not routinely recommended in low risk pregnant women due to no association between non-reactive NST and perinatal morbidity.

Keywords: Antepartum Fetal Monitoring, Non-stress test, Pregnancy

\section{Introduction}

Various non-invasive antepartum fetal surveillance techniques are available including fetal movement assessment, non-stress test (NST), biophysical profile (BPP), contraction stress test (CST), and maternal uterine artery and fetal umbilical artery Doppler velocimetry $[1,2]$. The aim of antepartum fetal surveillance is to confirm the well-being of the fetus and detect early neonatal injury [3]. NST is currently and widely used in antenatal clinics as a continuous measurement of fetal heart rate (FHR) because it is simple and does not harm pregnant women or their fetuses.

Early detection in the abnormal change of FHR is useful to prevent neonatal injury [4]. NST aims to confirm whether the brain of the fetus is sufficiently oxygenated. [2] Non-reactive NST is significantly associated with fetal distress and low Apgar scores [5]. Testing is recommended for pregnant women who are at risk of fetal hypoxic injury or fetal death. Indications for NST can be divided into three groups as follows: (1) Maternal indications such as diabetes, hypertension, cardiovascular diseases, anemia, kidney disease; (2) Fetal indications such as decrease fetal movement, abnormal fetal growth, post-term pregnancy, abnormal amniotic fluid; and
(3) Placental indications such as abnormal placentation, chronic abruption [6].

Due to the uncomplicated nature of the test, obstetricians in general practice often perform NST to pregnant women with minimal obstetric risks such as mothers with poor weight gain, decreased/ static weight, or passed date [7]. No clear evidence exists to support the benefit of NST in this group. Even though NST is not an invasive testing method, it is not free of charge and the patient is required to spend at least 20 minutes in the examination room. Moreover, NST results can influence the decisions of the obstetricians. Based on a previous study, non-reactive NST results increased the incidence of labor induction by $90 \%$ and doubled the rate of cesarean delivery [8]; therefore, patients may be subjected to unnecessary obstetrics procedures.This study was conducted to determine the prevalence of non-reactive NST for each indication and also identify the necessity for the test in low risk group. We anticipate that this knowledge will be useful in making decisions whether to offer NST to pregnant women.

\section{Materials and Methods}

This prospective observational study was conducted at the antenatal clinic, King Chulalongkorn Memorial Hospital. Pregnant 
women with gestation age of 32 weeks or more who had been offered NST by their obstetricians were invited to participate. We excluded pregnancies with antepartum diagnosed fetal congenital anomalies and those who have had multiple pregnancies. After the participants gave their informed consent, the participants were interviewed. This study was approved by the Institutional Review Board, Faculty of Medicine, Chulalongkorn University (IRB351/55). The high risk group was defined as participants at risk for fetal hypoxia or fetal death according to the antepartum surveillance bulletin of the American College of Obstetricians and Gynaecologists as described previously [6]. While the low risk group was defined as participants who did not show any maternal, fetal or placental risks. Demographic data and indications of NST were recorded in well-designed individual case records.

NST examination requires at least 20 minutes. Participants were placed in a supine position and a fetal heart rate monitor was attached to an abdominal belt. The participants were asked to record any fetal movements by clicking a button. In cases where there was suspicion that the baby was asleep, vibroacoustic stimulation was performed. Results were interpreted by at least two obstetricians. Results are classified as reactive or non-reactive. Reactive NST is diagnosed if there are at least two times of FHR acceleration in 20 minutes, with each acceleration 15 beats per minute (bpm) or more above baseline and lasting for at least 15 seconds. The baseline FHR should be between $110-160 \mathrm{bpm}$ with moderate variability of 6-25 bpm. If the FHR is elevated less than 15 bmp within a $20-40$ minute period, the interpretation is non-reactive. [9] Two obstetricians were required to agree with the interpretation of each result. If their analyses differed, a third obstetrician was consulted. If the final results showed a nonreactive then further investigations including biophysical profile, CST or ultrasonography were immediately performed. If the participants were offered NST more than once, the worst pattern was analyzed and included in the research results. All participants were monitored until delivery, with data and perinatal outcome collected and recorded in detail. Participants who did not deliver their babies at the King Chulalongkorn Memorial Hospital or lost their medical data were excluded from the study. Statistical analysis was performed using the Statistical Package for the Social Sciences (SPSS) for Windows, version 22. Descriptive data were analyzed using frequency and percentage, while significant associations between the categorical data were assessed by Fisher's exact test or Chi-square test. When the p-value was $<0.05$, this was considered statistically significant.

\section{Results}

A total of 1,536 pregnant women were offered NST. After obtaining informed consent, 1,297 women participated in this study. A total of 129 were not included because their medical records after follow-up was incomplete or unavailable. The remaining participants in final analysis were 1,168 participants. Mean age was $29.7 \pm 6.3$ years with mean gestational age on the testing day was $36.6 \pm 3.0$ weeks. Basic clinical characteristics of the participants are shown in (Table 1).

Ninety-three participants were offered NST twice; therefore, a total of 1,261 tests were analyzed in our study. A total of 782 NSTs were offered to low risk participants and 479 tests were offered to high risk pregnant women. For women in the low risk group, decrease in weight was the most common reason for requesting NST (275 cases). Maternal indications, especially diabetes mellitus were the most common indication for high risk participants (Table 2).

Table 1. Demographic data.

\begin{tabular}{|l|c|}
\hline \multicolumn{1}{|c|}{ Demographic data } & $\begin{array}{c}\text { Number of cases } \\
(\mathbf{N}=\mathbf{1 , 1 6 8})\end{array}$ \\
\hline Mean age, years (SD) & $29.7(6.3)$ \\
\hline Mean gestational age on the testing day, weeks (SD) & $36.6(3.0)$ \\
\hline Primigravida & $573(49.1 \%)$ \\
\hline Mean BMI, kg/m² (SD) & $22.8(4.8)$ \\
\hline Concomitant medical diseases & $412(35.3 \%)$ \\
\hline History of previous surgery & $278(23.8 \%)$ \\
\hline Smoking & $12(1.0 \%)$ \\
\hline Illicit drug use & $4(0.3 \%)$ \\
\hline Alcohol consumption & $16(1.4 \%)$ \\
\hline
\end{tabular}

Table 2. Indications for NST.

\begin{tabular}{|l|c|}
\hline \multicolumn{1}{|c|}{ Indications } & $\begin{array}{c}\text { Number } \\
\text { (Total number = 1,261) }\end{array}$ \\
\hline Low risk group & $782(62.0 \%)$ \\
Static weight gain & $193(15.3 \%)$ \\
Decrease in weight & $275(21.8 \%)$ \\
Poor weight gain & $84(6.7 \%)$ \\
Passed date (GA $40^{+1}-41^{+6}$ weeks) & $98(7.8 \%)$ \\
Other & $132(10.5 \%)$ \\
\hline High risk group & $479(38.0 \%)$ \\
Maternal indications & $346(27.4 \%)$ \\
Fetal indications & $119(9.4 \%)$ \\
Placental indications & $8(0.6 \%)$ \\
Maternal and fetal indications & $6(0.5 \%)$ \\
\hline
\end{tabular}

Obstetrics and perinatal outcomes were shown in (Table 3). Mean gestational age at delivery was $38.7 \pm 1.3$ weeks. The rate of spontaneous vaginal delivery was $53.5 \%$ and cesarean delivery rate was $43.5 \%$. Neonatal morbidity occurred in $11.9 \%$ of infants with $5.7 \%$ of them required admission. Four participants had non-reactive NST with overall prevalence at $0.32 \%$; three out of $782(0.38 \%)$ from the low risk group and one out of $479(0.21 \%)$ from the high risk group had non-reactive NST. Only one new born with non-reactive NST in high risk group was admitted in the Neonatal Intensive Care Unit (NICU) for 5 days due to meconium aspiration syndrome. This newborn had complete recovery and discharged with mother. The other three non- 
reactive NST in low risk group, intrauterine resuscitation was given, and repeated tests became reactive. These three newborns had no perinatal morbidity (Table 4). Fisher's exact test showed there was no association between NST result and pregnancy risk $(\mathrm{P}=1.00)$. There were no associations between NST results and adverse perinatal outcomes such as Apgar scores, neonatal morbidity, NICU admission, perinatal ventilator requirement and fetal anomalies (Table 5).

Table 3. Obstetrics and perinatal outcomes.

\begin{tabular}{|c|c|}
\hline Delivery data & Number of delivery $(\mathrm{N}=1,168)$ \\
\hline Mean gestational age at delivery, weeks (SD) & $38.7(1.3)$ \\
\hline Mean birth weight, grams (SD) & $3,142.5(455.5)$ \\
\hline \multicolumn{2}{|l|}{ Delivery route } \\
\hline Spontaneous vaginal delivery & $625(53.5 \%)$ \\
\hline Cesarean delivery & $507(43.5 \%)$ \\
\hline Forceps extraction & $30(2.6 \%)$ \\
\hline Vacuum extraction & $6(0.5 \%)$ \\
\hline \multicolumn{2}{|l|}{ Sex of fetus } \\
\hline Male & $621(53.2 \%)$ \\
\hline Female & $547(46.8 \%)$ \\
\hline \multicolumn{2}{|l|}{ Fetal anomalies } \\
\hline No & $1,127(96.5 \%)$ \\
\hline Yes & $41(3.5 \%)$ \\
\hline \multicolumn{2}{|l|}{ Neonatal morbidity } \\
\hline No & $1,029(88.1 \%)$ \\
\hline Yes & $139(11.9 \%)$ \\
\hline \multicolumn{2}{|l|}{ NICU admission } \\
\hline No & $1,120(94.3 \%)$ \\
\hline Yes & $66(5.7 \%)$ \\
\hline \multicolumn{2}{|l|}{ Ventilator required } \\
\hline No & $1,149(98.4 \%)$ \\
\hline Yes & $19(1.6 \%)$ \\
\hline
\end{tabular}

\section{Discussion}

This study showed the rate of non-reactive NSTs was low only $0.32 \%$. Most NSTs $(62.5 \%)$ were conducted in low risk participants. Prevalence of non-reactive testing was $0.38 \%$ and $0.21 \%$ in the low and high risk pregnant women, respectively. Overall prevalence of nonreactive NSTs in our study was very low compared to previous studies. Rayburn et al. conducted a prospective study of 315 pregnancies and determined $12 \%$ of NSTs had non-reactive patterns [10], while Abitbol et al. reported $10.9 \%$ of patients had non-reactive NSTs [11]. The results from these two studies were different compared to our study. These 2 studies were conducted before 1990, most patients had risk factors and different terminologies of abnormal NST result might be plausible explanation. The use of vibroacoustic stimulators in these two previous studies might be another possibility. There is clear evidence that vibroacoustic stimulation can reduce testing time but can contribute to higher rates of false non-reactive results [12].

Table 4. Clinical characteristics of non-reactive NST cases.

\begin{tabular}{|c|c|c|c|c|}
\hline Gravida & G4P1 & G1P0 & G2P1 & G1P0 \\
\hline $\begin{array}{l}\text { GA at testing day } \\
\text { (weeks) }\end{array}$ & 39 & 37 & 40 & 39 \\
\hline $\begin{array}{l}\text { Indication for } \\
\text { NST }\end{array}$ & $\begin{array}{l}\text { Gestation } \\
\text { diabetes } \\
\text { (High risk) }\end{array}$ & $\begin{array}{l}\text { Decrease in } \\
\text { weight } \\
\text { (Low risk ) }\end{array}$ & $\begin{array}{l}\text { Decrease } \\
\text { in weight } \\
\text { (Low risk) }\end{array}$ & $\begin{array}{l}\text { Unspecified } \\
\text { (Low risk) }\end{array}$ \\
\hline Delivery route & $\begin{array}{l}\text { Emergency } \\
\text { cesarean } \\
\text { section }\end{array}$ & $\begin{array}{l}\text { Cesarean section } \\
\text { due to breech } \\
\text { presentation }\end{array}$ & $\begin{array}{l}\text { Vaginal } \\
\text { delivery }\end{array}$ & $\begin{array}{l}\text { Cesarean } \\
\text { section due } \\
\text { to CPD }\end{array}$ \\
\hline $\begin{array}{l}\text { Neonatal } \\
\text { outcomes }\end{array}$ & $\begin{array}{l}\text { Male fetus } \\
3,325 \text { grams }\end{array}$ & $\begin{array}{l}\text { Male fetus 2,935 } \\
\text { grams }\end{array}$ & $\begin{array}{l}\text { Male fetus } \\
2,800 \\
\text { grams }\end{array}$ & $\begin{array}{l}\text { Male fetus } \\
3,220 \text { grams }\end{array}$ \\
\hline $\begin{array}{l}\text { APGAR scores } \\
\text { at } 1 \text { and } 5 \text { mins }\end{array}$ & 9,9 & 9,10 & 9,10 & 9,10 \\
\hline $\begin{array}{l}\text { Perinatal } \\
\text { morbidity }\end{array}$ & $\begin{array}{l}\text { Maconium } \\
\text { aspiration } \\
\text { syndrome } \\
5 \text { days } \\
\text { of NICU } \\
\text { admission }\end{array}$ & No & No & No \\
\hline
\end{tabular}

$\mathrm{GA}=$ Gestational age

Data from our study confirmed that offering NST to low risk pregnant women was pointless, waste of time and resources. Although, NST is simple and widespread use, there is poor evidence that it can reduce perinatal morbidity or mortality. One major drawback is high frequency of false positive rates. Pregnant women usually placed on supine position during the test. Compression of abdominal aorta results in reduction of uterine blood flow and associated with fetal heart rate change. [11] Repeated test in lateral decubitus position usually returns into normal results. Our study confirmed that nonreactive NST in low risk participants did not associated with perinatal morbidity. However, it may not conclude in high risk participants due to very low percentage of non-reactive results. Only 1 patients with maternal risk factors (gestational diabetes) showed non-reactive NST and meconium aspiration syndrome was diagnosed in this newborn. Despite low specificity to predict perinatal morbidity, antepartum NST is still recommended to use only in pregnant women with risk factors for adverse perinatal outcome [13].

To the best of our knowledge, this is the first and large study that looked at the results of NST in low risk pregnant women. The results indicated that NST is unnecessary for low risk pregnant women. However, there were some limitations in our study. Firstly, the prevalence of non-reactive NST was very low in both low and high risk pregnant women. As this result, it may not have enough power 
to significantly confirm our findings. Secondly, about $10 \%$ of the pregnant women who were lost to follow-up were excluded from the final analysis.

Table 5. Association between NST results and perinatal outcomes including Apgar score, neonatal morbidity, NICU admission, perinatal ventilator requirement and fetal anomalies.

\begin{tabular}{|c|c|c|c|c|}
\hline & & \multicolumn{2}{|c|}{ NST } & \multirow{2}{*}{ P value } \\
\hline \multicolumn{2}{|c|}{ Perinatal outcomes } & Reactive & Non-reactive & \\
\hline \multirow{2}{*}{ Apgar score at $1 \mathrm{~min}^{*}$} & $<7$ & 25 & 0 & \multirow{2}{*}{1.00} \\
\hline & $7-10$ & 1,138 & 4 & \\
\hline \multirow{2}{*}{ Apgar score at $5 \mathrm{~min}^{*}$} & $<7$ & 3 & 0 & \multirow{2}{*}{1.00} \\
\hline & $7-10$ & 1,160 & 4 & \\
\hline \multirow{2}{*}{ Neonatal morbidity } & Yes & 138 & 1 & 0.40 \\
\hline & No & 1,026 & 3 & \\
\hline \multirow{2}{*}{ NICU admission } & Yes & 65 & 1 & \multirow{2}{*}{0.21} \\
\hline & No & 1,099 & 3 & \\
\hline \multirow{2}{*}{ Perinatal ventilator need } & Yes & 19 & 0 & \multirow{2}{*}{1.00} \\
\hline & No & 1,145 & 4 & \\
\hline \multirow{2}{*}{ Fetal anomalies } & Yes & 41 & 0 & \multirow{2}{*}{1.00} \\
\hline & No & 1,123 & 4 & \\
\hline
\end{tabular}

* one missing data

\section{Conclusions}

Overall, non-reactive NST was $0.32 \%(0.38 \%$ in low risk and $0.21 \%$ in high risk groups). NST is unnecessary for low risk pregnant women. There was no association between NST results and adverse perinatal outcomes including Apgar score, neonatal morbidity, NICU admission, perinatal ventilator requirements and fetal anomalies.

\section{Declaration of interests}

The authors declared no conflicts of interest.

\section{Acknowledgement}

This study was supported by Ratchadapiseksompoch Fund (RA55/69), Faculty of Medicine, Chulalongkorn University, Bangkok, Thailand.

\section{References}

1. Williams KP, Farquharson DF, Bebbington M, Dansereau J, Galerneau F, et al (2003) Screening for fetal well-being in a high-risk pregnant population comparing the nonstress test with umbilical artery Doppler velocimetry: a randomized controlled clinical trial. Am J Obstet Gynecol 188: 1366-1371.

2. Liston R, Sawchuck D, Young D (2018) No. 197a-Fetal Health Surveillance: Antepartum Consensus Guideline. J Obstet Gynaecol Can 40: 251-271.

3. Esin S (2014) Factors that increase reactivity during fetal nonstress testing. Curr Opin Obstet Gynecol 26: 61-66.

4. Gobillot S, Fontecave-Jallon J, Equy V, Rivet B, Gumery PY, et al. (2018) Noninvasive fetal monitoring using electrocardiography and phonocardiography: A preliminary study. J Gynecol Obstet Hum Reprod 47: 455-459. [crossref]

5. Flynn AM, Kelly J (1977) Evaluation of fetal wellbeing by antepartum fetal heart monitoring. Br Med J 1: 936-939. [crossref]
6. [No authors listed] (2000) ACOG practice bulletin. Antepartum fetal surveillance. Number 9, October 1999 (replaces Technical Bulletin Number 188, January 1994). Clinical management guidelines for obstetrician-gynecologists. Int J Gynaecol Obstet 68: 175-185. [crossref]

7. Mancuso A, De Vivo A, Fanara G, Denaro A, Lagana D, et al. (2008) Effects of antepartum electronic fetal monitoring on maternal emotional state. Acta Obstet Gynecol Scand 87: 184-189.

8. Evertson LR, Gauthier RJ, Schifrin BS, Paul RH (1979) Antepartum fetal heart rate testing. I. Evolution of the nonstress test. Am J Obstet Gynecol 133: 29-33. [crossref]

9. Preboth M (2000) ACOG guidelines on antepartum fetal surveillance. American College of Obstetricians and Gynecologists. Am Fam Physician 62: 1184, 1187 1188. [crossref]

10. Rayburn WF, Motley ME, Zuspan FP (1982) Conditions affecting nonstress test results. Obstet Gynecol 59: 490-493. [crossref]

11. Abitbol MM, Monheit AG, Poje J, Baker MA (1986) Nonstress test and maternal position. Obstet Gynecol 68: 310-316. [crossref]

12. Smith CV, Phelan JP, Platt LD, Broussard P, Paul RH (1986) Fetal acoustic stimulation testing. II. A randomized clinical comparison with the nonstress test. Am J Obstet Gynecol 155: 131-134.

13. Freeman RK, Anderson G, Dorchester W (1982) A prospective multi-institutional study of antepartum fetal heart rate monitoring. II. Contraction stress test versus nonstress test for primary surveillance. Am J Obstet Gynecol 143: 778-781.

\section{Citation:}

Tarinee Manchana, Pinyada Panyavaranant, Patou Tantbironj, Porntip Sirayapiwat, Ruangsak Lertkachonsuk and Surang Triratanachat (2019) Prevalence of Nonreactive Non-Stress Test in Low Versus High Risk Pregnancy. Integr Gyn Obstet $J$ Volume 2(1): 1-4. 